\title{
Association of syndactyly, ectodermal dysplasia, and cleft lip and palate: report of two sibs from Turkey
}

\author{
GÖNÜL OGUUR AND MEMNUNE YÜKSEL \\ From the Institute of Child Health, University of Istanbul, ÇapalIstanbul, Turkey.
}

SUMmaRY Two Turkish sibs, products of a second cousin marriage, with tetramelic syndactyly, ectodermal dysplasia, cleft lip and palate, renal anomalies, and mental retardation are reported. Similarities between these two brothers and previously reported cases and their mode of transmission are discussed.

In 1961, Rosselli and Gulienetti ${ }^{1}$ reported four patients with hypohidrosis, hypotrichosis, microdontia, dystrophic nails, cleft lip and palate, deformities of the extremities, and malformations of the genitourinary system. Syndactyly was the predominant digital deformity. Phenotypically normal parents who were first cousins suggested an autosomal recessive mode of inheritance in two of their cases who were sibs. In 1970 , a very similar clinical condition was described as the EEC syndrome (ectrodactyly-ectodermal dysplasia-cleft lip/palate) by Rudiger $e t a l^{2}$ and Freire-Maia ${ }^{3}$ almost simultaneously. Other reports ${ }^{4-6}$ suggested autosomal dominant transmission in these cases. We report two male sibs from Turkey who show tetramelic syndactyly, ectodermal dysplasia, cleft lip and palate, renal anomalies, and mental retardation. We discuss the similarities between these two sibs and previously reported cases and review their mode of transmission.

\section{Family history and case reports}

The pedigree of the family is shown in fig 1 . The parents were phenotypically normal first cousins. Their physical examination revealed no congenital malformations except that the mother had partial hearing loss. Her audiometric tests revealed a neurogenic type of deafness. It was stated that her aunt (her father's sister) and paternal grandmother also had hearing problems. The father's family showed no problems in the previous two generations but his paternal grandmother's brother was stated to have syndactyly and one of this subject's relatives was said to have a cleft lip deformity. Unfortunately no more details were available. The family's first offspring was aborted in early pregnancy. The second, a healthy boy, is 11 years old. The third pregnancy ended as a stillbirth but had no congenital malformations. The fourth and fifth children are our probands.

\section{CASE 1}

The older son (IV.4, fig 1) was born on 24.11.77, weighing $2300 \mathrm{~g}$, after a normal 32 week gestation. No perinatal complications were observed. Bilateral cleft lip and palate and syndactyly of both hands and both feet were noticed at birth. In the postnatal period, motor development was stated to be slightly retarded. When he was six months old, an operation
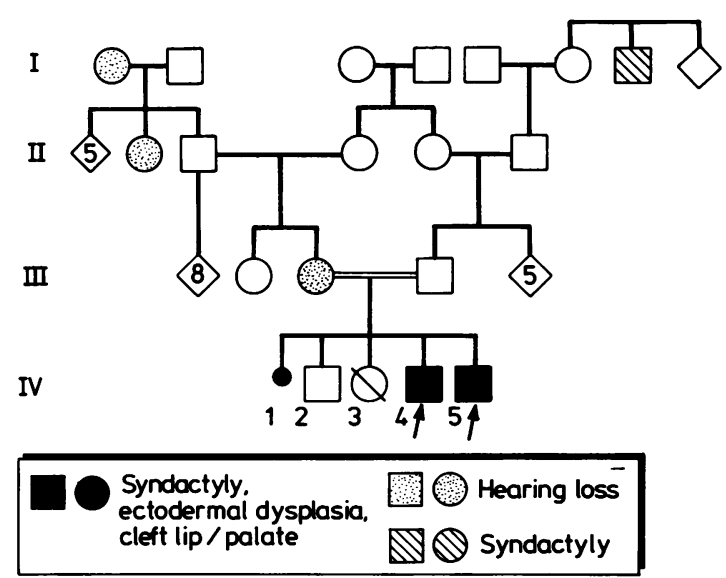

FIG 1 Family pedigree. 
for the repair of the bilateral cleft lip was performed. At the age of three years his cleft palate was also repaired. The two brothers were first referred to our Paediatric-Genetic Section from the Department of Psychiatry where they were already being followed for their mental retardation.

On physical examination the scalp hair and eyebrows were sparse, light, short, thin, and kinky. The eyebrows were especially sparse in their lateral halves. His face was narrowed with a happy expression. He had a broad, flat nose, low set, large ears, and a prominent chin. His upper lip showed surgical scars related to cleft lip and palate operations (fig 2). The teeth were all very carious and notched. The lower incisors were microdontic and cone shaped. The upper mediolateral incisor was lacking. There was a slight impairment of hearing but, because of lack of cooperation, audiometric analysis could not be performed. There was partial syndactyly of the second, third, and fourth fingers of both hands with interdigital webbing, and of the second and third toes of both feet (figs 3 and 4). His skin was significantly thickened and dry, especially on the extremities. The parents had seldom noted sweating. The nipples and areolae were reduced in size. Evaluation of psychomotor development showed moderate retardation. The speech disorder was attributed to anatomical lip and palate impairment and to his psychomotor retardation. The remainder of the physical examination was normal. $X$ rays of the skull and long bones were all normal. Intravenous pyelogram showed slight obstruction of the ureterovesical junction-extrarenal pelvis and spina bifida. Bone age was retarded by one year.

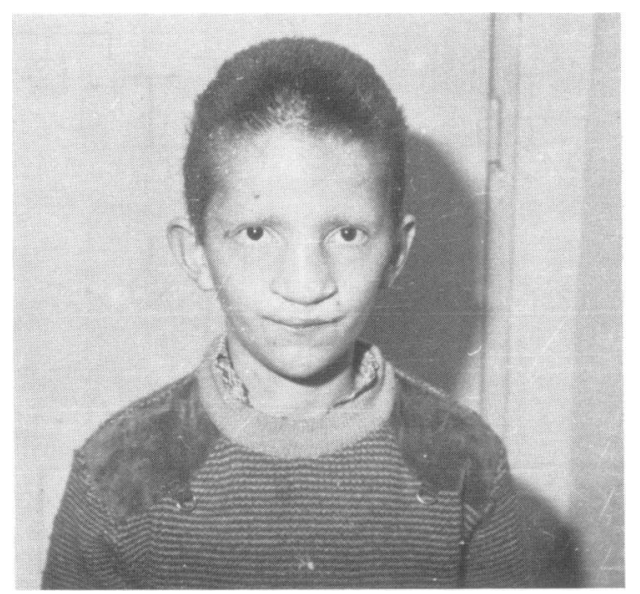

FIG 2 Case 1 .
Other laboratory tests including EEG, haemogram, renal function, and urine culture showed normal results.

CASE 2

The brother of case 1 was born on 2.2.79, weighing $\overparen{\nabla}$ $2500 \mathrm{~g}$, after a normal 40 week gestation (IV.5, fig 1). When first seen for genetic consultation, he was $\infty$ noticed to have strikingly similar characteristics to $\overrightarrow{0}$ his brother, with bilateral cleft lip and palate and $\overrightarrow{\vec{\omega}}$ tetramelic syndactyly. He also had psychomotor $\omega$ retardation with a Stanford-Binet score of 44 . The Denver developmental test showed retardation of approximately one and a half years. His skin was dry ज and thickened on the extremities and hypohidrosis was also a problem. He had a similarly narrowed ${ }_{y}$

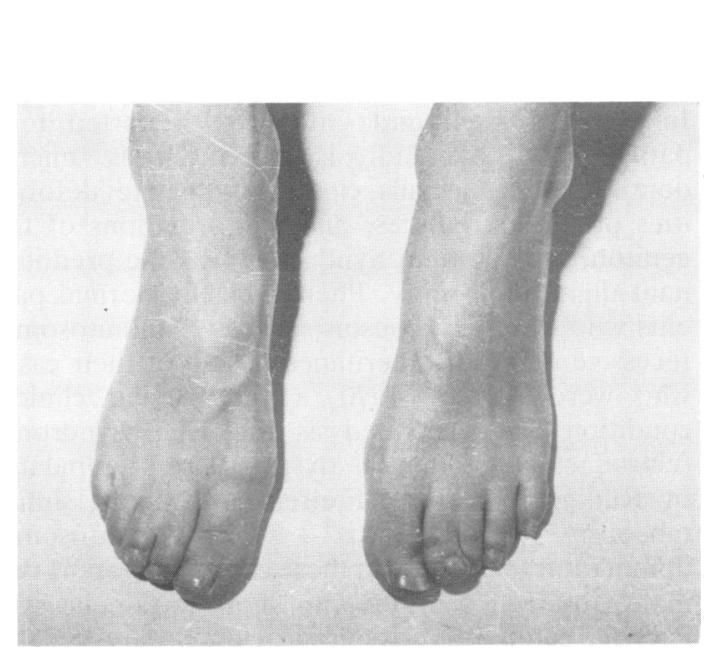

FIG 3 Feet of case 1.

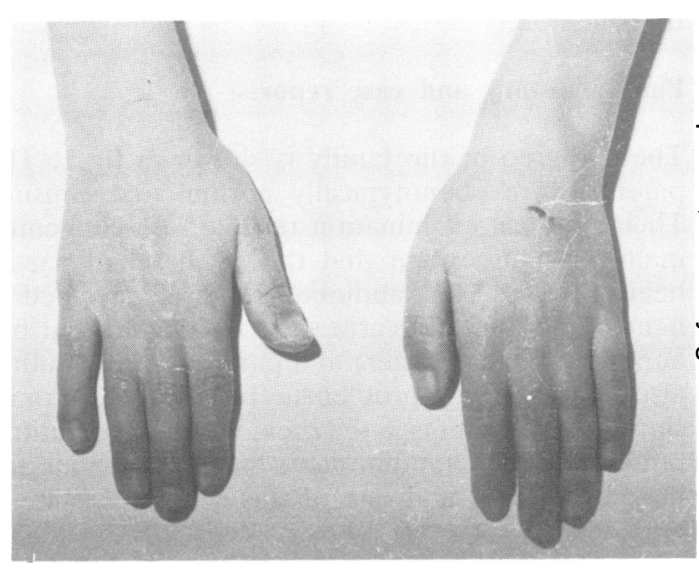

FIG 4 Hands of case 1. 


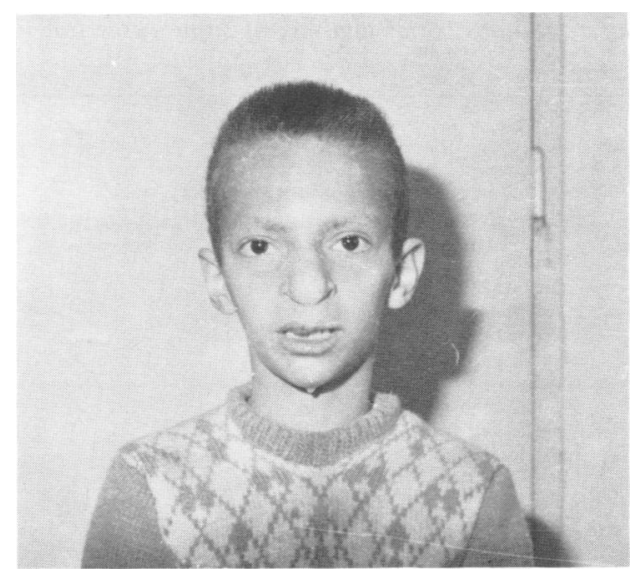

FIG 5 Case 2.

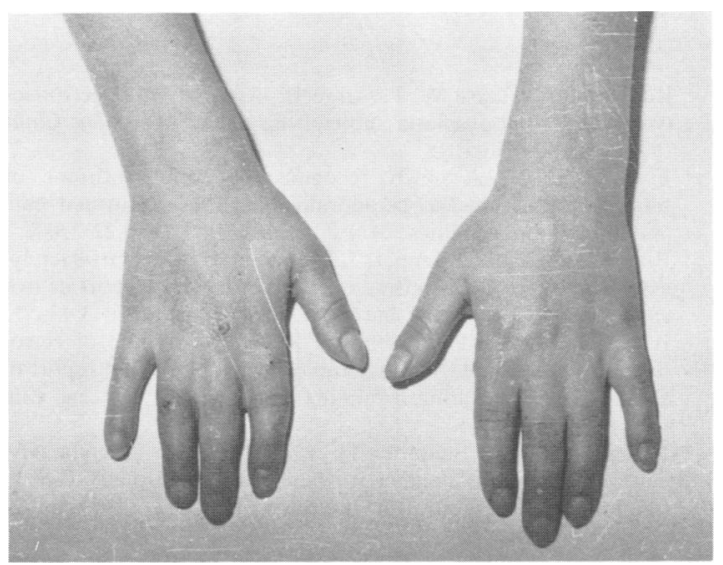

FIG 6 Hands of case 2.

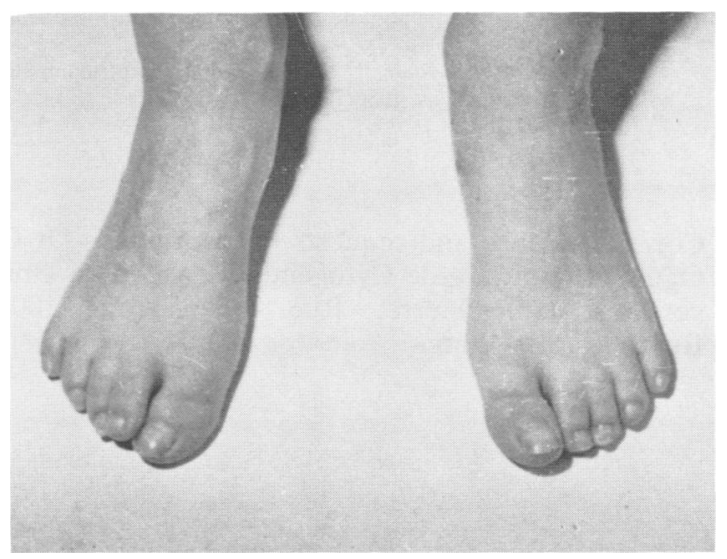

FIG 7 Feet of case 2 . face with a flat, broad nose, low set ears, and small, carious, and notched teeth. Scalp hair and eyebrows were sparse, light, kinky, thin, and short (fig 5). His bilateral cleft lip and palate deformity was also repaired surgically, but owing to incomplete healing there was still a $1 \mathrm{~cm}$ wide median cleft of the hard palate. He had no hearing problems. There was partial syndactyly between the second, third, and fourth fingers of both hands with striking interdigital webbing (fig 6) and on both feet there was partial syndactyly between the second and third toes (fig 7). His nipples and areolae were also hypoplastic. No radiological evaluation of the skeletal system was performed but IVP showed slight ptosis of the right kidney, dilatation of the calices, and hydronephrotic changes on the left. He also had a neurogenic bladder.

\section{Discussion}

To our knowledge, up to date reports relating to the EEC syndrome and similar conditions show uncertainty about the mode of inheritance. Autosomal dominant inheritance with variable expressivity and incomplete penetrance, ${ }^{4-6}$ as well as autosomal recessive inheritance, ${ }^{137}$ have been reported (table). Recently it has been suggested that the EEC syndrome with complete and incomplete forms, odontotrichomelic syndrome (OS), and other similar conditions form a 'community' or 'family' of different although very similar syndromes. ${ }^{9} \mathrm{We}$ believe the two brothers described here belong to this 'community'. They have similar problems to the patients of Rosselli and Gulienetti ${ }^{1}$ and Bowen and Armstrong, ${ }^{8}$ showing tetramelic syndactyly, ectodermal dysplasia with abnormalities of scalp hair, and teeth, and hidrotic problems, and bilateral cleft lip and palate. In addition, both were mentally retarded and showed some renal anomalies. The syndactyly was cutaneous in type and involved both the fingers and toes. The function of the extremities was not profoundly affected though cases reported by most of the other authors have had more severe limb defects (table). Sparse and kinky hair with small, carious teeth, broad, flat nose, and a prominent chin gave a typical facial appearance to both our patients, similar to the cases of Brill et al. ${ }^{5}$ Their skin was dry and thickened and severe sweating was absent according to the parents. A formal sweat test was not performed. Psychomotor retardation and genitourinary tract anomalies were similar to those previously reported. ${ }^{1-5}$

To our knowledge these two brothers represent the third family report of syndactyly, ectodermal dysplasia, and cleft lip and palate. The cases of Bowen and Armstrong ${ }^{8}$ differ from ours and from 
TABLE EEC syndrome, odontotrichomelic syndrome, and similar conditions: brief analysis of some cases previously reported.

\begin{tabular}{|c|c|c|c|c|c|c|}
\hline Reference & $\begin{array}{l}\text { Mode of } \\
\text { transmission }\end{array}$ & $S$ & $E$ & $E D$ & $C L / P$ & Other \\
\hline 1 & AR? & + & & + & + & Genitourinary malformation, multiple pterygia \\
\hline 7 & AR?/AD? & & + & $?$ & + & Renal abnormalities \\
\hline 3 & AR & & + & + & $C L$ & $\begin{array}{l}\text { Disorders of metabolism, } \\
\text { genitourinary abnormalities, } \\
\text { abnormal EEG and ECG. mental } \\
\text { retardation }\end{array}$ \\
\hline 2 & $\mathrm{AD}$ & & + & + & + & Psychomotor retardation \\
\hline 4 & $\mathrm{AD}$ & + & + & + & + & Mental retardation \\
\hline 5 & AD & & + & + & $\mathrm{CP}$ & $\begin{array}{l}\text { Carcinoma of the cervix, } \\
\text { renal abnormalities, } \\
\text { sickle cell trait }\end{array}$ \\
\hline 6 & $\mathrm{AD}$ & & + & + & $\mathrm{CP}$ & Imperforate anus \\
\hline 8 & $\mathrm{AD} / \mathrm{AR}$ ? & + & & + & + & $\begin{array}{l}\text { Mental retardation, adhesions } \\
\text { between eyclids, abnormal EEG, } \\
\text { hyperpigmentation, growth retardation, } \\
\text { cicatricial atrophy of scalp }\end{array}$ \\
\hline This report & AR? & + & & + & + & $\begin{array}{l}\text { Renal abnormalities, mental } \\
\text { retardation }\end{array}$ \\
\hline
\end{tabular}

$\mathrm{S}=$ syndactyly. $\mathrm{E}=$ ectrodactyly, $\mathrm{ED}=$ ectodermal dysplasia, $\mathrm{CL} / \mathrm{P}=$ cleft lip/palate. $\mathrm{AR}=$ autosomal recessive. $\mathrm{AD}=$ autosomal dominant .

most of the similar reported cases by having adhesions between the eyelids, genital hypoplasia, hyperpigmentation, cicatricial atrophy of the scalp, an abnormal EEG, and severe undernutrition.

The parents were both examined physically and were found to have no congenital malformations. Partial hearing loss in the mother was believed to be a dominant type because of the family history. With two sibs being affected, and with the phenotypically normal parents being first cousins, autosomal recessive inheritance is very likely in our family. $\mathrm{X}$ linked transmission, though theoretically valid, is less likely. The two relatives mentioned in the family history, with syndactyly and cleft lip respectively, are difficult to explain under autosomal recessive inheritance. However, they were not available for study and their history was inadequate. We believe that EEC syndrome, odontotrichomelic syndrome, and similar conditions form, as Pinheiro and FreireMaia ${ }^{9}$ have suggested, a 'community' or 'family' showing genetic heterogeneity. We suggest our cases belong to this community representing either a variant of EEC syndrome or a new syndrome with autosomal recessive inheritance.

\section{References}

1 Rosselli D, Gulienetti R. Ectodermal dysplasia. Br J Plast Surg 1961;14:190-204.
2 Rudiger RA, Haase W, Passarge E. Association of ectrodactyly, ectodermal dysplasia and cleft lip-palate. Am J Dis Childe 1970;120:160-3.

${ }^{3}$ Freire-Maia N. A newly recognized genetic syndrome of tetramelic deficiencies, ectodermal dysplasia, deformed ears and other abnormalities. Am J Hum Genet 1970;22:370-7. 主 ${ }^{4}$ Bixler D, Spivack J, Bennett J, Christian JC. The ectrodactyly ectodermal dysplasia-clefting (EEC) syndrome. Report of two cases and review of the literature. Clin Genet 1971;3:43-51. ${ }^{5}$ Brill CB, Hsu LYF, Hirschhorn K. The syndrome of ectro $\mathbb{Q}$ dactyly, ectodermal dysplasia and cleft lip and palate: report of a family demonstrating a dominant inheritance pattern. Clin Genet 1972;3:295-302.

- Rosenmann A, Shapira T, Cohen MM. Ectrodactyly ectodermal dysplasia and cleft palate (EEC syndrome). Reporo of a family and review of the literature. Clin Genet 1976;9:34753 .

7 Walker JC, Clodius L. The syndromes of cleft lip, cleft palat and lobsterclaw deformitics of hands and feet. Plast Reconst $\bar{S}$ Surg 1963;32:627-36.

${ }^{8}$ Bowen P. Armstrong HB. Ectodermal dysplasia, mentai retardation, cleft lip/palate and other anomalies in three sibs 3 Clin Genet 1976;9:35-42.

${ }^{9}$ Pinheiro M, Freire-Maia N. EEC and odontotrichomelie syndromes. Clin Genet 1980;17:363-6.

Correspondence and requests for reprints to $\mathrm{Dr} Q \mathrm{~S}$ Oğur, Laboratoire de Cytogénétique, Hôpital Uniહ versitaire Saint-Pierre, Rue Haute 322, 100 (2) Bruxelles, Belgium. 